\title{
Assimilate limitation compensating factors under environmental stresses in wheat
}

\author{
Vidisha Thakur ${ }^{1}$ and Jagadish Rane ${ }^{2}$ \\ ${ }^{1}$ BanasthaliVidyapeeth, Jaipur, Rajasthan- 304022 \\ ${ }^{2}$ ICAR-National Institute of Abiotic Stress Management, Malegaon, Baramati, Pune- 413115
}

\section{Article history}

Received: 8 Oct., 2020

Revised : 15 Dec., 2020

Accepted: 19 Dec., 2020

\section{Citation}

Thakur V and J Rane. 2020. Assimilate limitation compensating factors under environmental stresses in wheat. Journal of Cereal Research 12(3): 213-228. http:// doi.org/10.25174/2582-2675/2020/105762

*Corresponding author

Email: vidisha.thakur30@gmail.com

(C) Society for Advancement of Wheat and Barley Research

\begin{abstract}
In recent years, considerable efforts have been made to understand the factors controlling grain weight in wheat. In addition to sink capacity, the supply of assimilates for developing grain determines its weight. The current photosynthesis of the flag leaf is the most important source of assimilation, and the onset and rate of senescence are important factors for determining grain yield. Hence stress induced leaf senescence can reduce the supply of assimilates for grains. Under such conditions, assimilate contributions of stored non structural carbohydrates in stem and photosynthesis of non foliar parts of the plant such as spike are crucial for grain development. Non structural carbohydrates in wheat stem have been estimated and efforts have been made to reveal the mechanisms of assimilate partitioning. The hormone levels and activities of enzymes involved in assimilate partitioning and carbohydrate metabolism in wheat stem and grains have been significantly correlated with grain filling in wheat. Remobilization efficiency of stem reserves is increased under heat or drought stress along with increase in the proteins associated with senescence and Reactive Oxygen Species handling in the tolerant cultivars. The heat and drought tolerant wheat cultivars have a higher Water Soluble Carbohydrates content in stem, higher mobilization efficiency, longer duration of grain filling and stronger sink activity. However, some of the key issues such as intra-spike assimilation distribution have not been sufficiently addressed. This review has been compiled for information related to assimilate supply to the developing wheat grain under stress conditions and also enlists opportunities to translate this knowledge into traits for improvement of climate resilience in wheat.
\end{abstract}

Keywords: Grain weight, assimilate, photosynthesis, stem reserves, intra-spike assimilation

\section{Introduction}

Productivity of wheat cultivar is the function of grain weight and grain numbers per unit area irrespective of growth environments. While grain number is determined at early phases of plant growth, the grain weight is largely determined by ambient and edaphic conditions that prevail during grain development. The individual grain weight is an important trait for increasing the yield potential of wheat (Xie et al., 2015) and is generally reduced when plant experiences stress during grain filling
(Fig. 1).The time period of grain filling and its rate has significant effect on final yield (Motzo et al. 2004; Sadras and Egli, 2008). Grain filling duration is between 362 to 400 growing degree days (GDD) and the rate of grain filling ranges from 0.12 to $0.22 \mathrm{mg} \mathrm{GDD}^{-1}$ depending upon the environment and genotype (Xiaoli et al., 2018). Miralles and slafer (1995) stated that rate of grain filling varies at different positions in the spike resulting in differences in grain weight. Carpel weight is directly 
related to final grain weight in case of central spikelets (Hasan et al., 2011).Wheat breeding has created substantial reduction in nitrogen and phosphorus levels in grain as a result of biomass dilution (Ortiz-Monasterio et al., 1997). Genetic variation has been observed for micronutrient concentration in grains (Calderini and Ortiz-Monasterio, 2003). Grain nutrient concentration tends to get diluted at the cost of improvement in weight. However grain position in the spike has been correlated to nitrogen concentration (Simmons and Moss, 1978). Within the spikelets, the distal lighter grains had low $\mathrm{N}$ content than the heavier proximal grains on central and basal spikelets (Herzog and Stamp, 1983). This suggests that nutrient content of the grains is affected by grain position in spike. Therefore, nutrient partitioning within spike and dilution effect both need to be considered in subsequent breeding programs for yield improvement. Previous efforts have focused on higher grain number per square meter than enhancement in grain size. The distal grain setting in spikelets has contributed to increase in the grain number (Calderini and Slafer, 1999). However, the selection for additional grains in spikelets is compromising the nutritional quality of grains (Calderini and Ortiz-Monasterio, 2003).

Wheat crop often gets exposed to drought and high temperature during grain growth particularly in subtropical conditions (Rane et al., 2007). Under drought stress wheat yield is mostly decreased by $50 \%$ or less of the irrigated control (Yu et al., 2014). A mild terminal drought stress (60\% relative soil moisture content) has been found to decrease the grain yield by more reduction in the kernel weight than the grain number (Rasheed et al., 2014, Zhang et al., 2014). Hence, any efforts to improve grain yield of wheat under these stresses should consider insights into the mechanisms of grain development and also the supply of assimilates for developing grains particularly when plants experience stress. As depicted in Fig 1, the major causes of decrease in grain weight can be damage to the leaves which serve as main source of assimilate, impaired metabolism and anatomical defects in assimilate supplying parts of the plant. The conceptual illustration in the figure emphasizes that a series of events that occur mainly contributes to reduction in overall grain weight as well as intra-spike discrimination in distribution of assimilates while the sink size and its variation within the spike is largely governed by genetic make of the genotypes. Both the sink capacity and the sources capacity thus determine the grain weight while any of the events in assimilate supply to grain can be an opportunity point for improving the resilience of grain development process to stresses like drought and high temperature. The following sections explore such opportunities for improvement of grain weight of wheat under abiotic stress conditions caused by drought and high ambient temperature. Del Pozo et. al. (2016) found that drought stress decreased the grain yield per spike by $16.2 \%$ in the tolerant cultivar and by $27.9 \%$ in sensitive cultivar. But under combined heat and drought stress, the same cultivar did not show high tolerance. High temperature significantly reduced the grain weight and number of grains in wheat ( $\mathrm{Su} e t$ al. 2011). It has been reported that during grain filling with every $1^{\circ} \mathrm{C}$ rise in temperature above $18^{\circ} \mathrm{C}$, there is $3 \%-5 \%$ reduction in single grain weight ( $\mathrm{Hu}$ et al 2016). Several other studies have reported that postanthesis rise in ambient temperature resulted in 9 to $15 \%$ reduction in individual grain weight. The cumulative effects of high temperature expressed as heat sum ${ }^{\circ} \mathrm{C} \times \mathrm{h}$, the reduction in grain weight equated to $0.03 \%$ to $0.06 \%$ per ${ }^{\circ} \mathrm{C} \mathrm{h}$ $\left(>32^{\circ} \mathrm{C}\right.$ ) (Ling et al., 2013). Studies have demonstrated that short periods of high temperature (near $40^{\circ} \mathrm{C}$ ) during grain filling result in progressive reduction in sensitivity. The stress applied at 15, 30 and 40 DAA caused average reduction in individual grain weight by 15,9 , and $1 \%$, respectively (Chang et al., 2015; Wang et al., 2012). A day of high temperature $\left(40 / 21^{\circ} \mathrm{C}\right.$ day/night $)$ during grain filling decreased the individual grain weight by $10-30 \%$ compared with a control $\left(21 / 16^{\circ} \mathrm{C}\right.$ day/night) (Campbell et al. 1999; Groos et al. 2003). Mahrookashani et al. (2017) observed that the individual grain weight was decreased by $13 \%-27 \%$ under drought stress and by $43 \%-83 \%$ under combined heat and drought stress. Heat stress significantly decreased grain number by $14 \%-28 \%$, grain yield by $16 \%-25 \%$ and straw yield by $15 \%-25 \%$. Also, the response of cultivars were similar for heat but different for drought and combined heat and drought treatments.

\section{Contribution of leaves to grain filling in wheat}

Flag leaf photosynthesis in wheat contributes about $30-50 \%$ of the assimilates for grain filling (SylvesterBradley, 1990) and initiation of grain filling coincides with the onset of senescence. There are characteristic changes in the anatomy of a leaf under stress conditions which can be considered as a significant manifestation of the regulation of photosynthesis at the morphological 


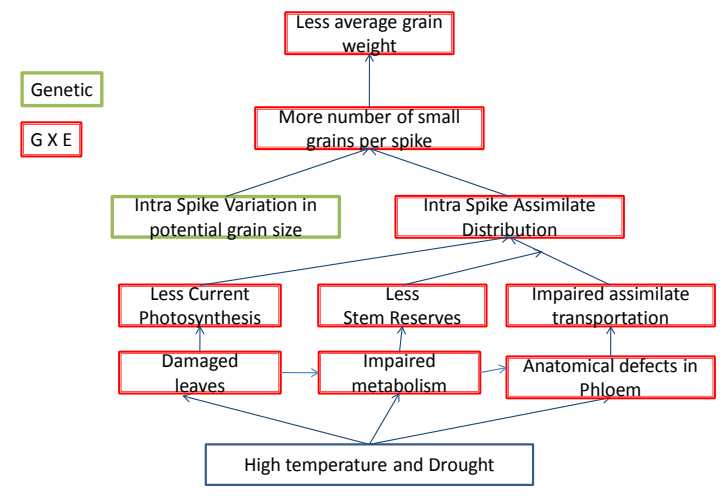

Fig. 1 Genotype $(\mathrm{G})$ x environment $(\mathrm{E})$ interaction and genetic factors responsible for reduction in grain weight

level. It follows that moderate water limitation during vegetative phase will decrease growth of leaf thus decreasing photosynthesis. As drought intensifies and leaf water potential reach -1.5 MPa, closing of stomata occurs and further decreases photosynthesis (Acevedo et al. 1991; Kobata et al., 1992; Palta et al., 1994). As $\mathrm{CO}_{2}$ in the leaf decreases, electron transport is inhibited. Photoinhibition causes damage to the photosynthetic system of leaf (Long et al., 1994). Maintenance of the plant's water status and open stomata is therefore important not only for cooling but also for maintaining a high conductance for $\mathrm{CO}_{2}$, which keeps photo-synthetic dark reactions going and electron transport functioning (Loomis and Amthor, 1996). Enhanced chlorophyll fluorescence is observed when light harvesting exceeds the capacity of the dark reactions; consequently, fluorescence measurements are now used widely for detection of stress effects on crops (Seaton and Walker, 1990).

Maximum loss of grain yield occurs when the wheat plants are exposed to water scarcity at flowering and grain filling stages as a consequence of substantial decline in the rate of photosynthesis and hence assimilate supply for grains. This is the outcome of constrained metabolic performance (eg. degradation of chloroplasts and closure of stomata (Pinheiro et al. 2000). Plant leaf gas exchange has been studied and a decrease of $64 \%$ in net photosynthesis has been reported under severe stress (relative soil water content, RSWC $<40 \%)$, whereas under mild stress $(40 \%<$ RSWC $<55 \%$ ) the decrease is only $28 \%$ (Yan et al. 2016).

Heat stress breaks down chlorophyll, impedes photosynthesis rate and induces leaf senescence thereby affecting grain weight and quality. High temperature during grain filling has been reported to reveal significant increase in level of proteins involved in photosynthesis in tolerant genotypes implying their critical role in tolerance (Wang et al., 2015). Heat-shock proteins were reported to be induced in the leaves by drought (Wang $e t$ al., 2003), cold (Sabehat et al., 1998) and heat (Lee et al., 2007) repairing degraded proteins. The proteins related to photosynthesis significantly increased by heat stress, presumably to protect the photosynthetic machinery from heat (Law and Crafts-Bradner, 2001). The proteins related to reactive oxygen species scavenging counteract the damage due to heat stress. The defense processes require energy which is produced by increased level of energy metabolism related proteins (Yan et al., 2006).

The relationship between grain yield and rate of photosynthesis is not straightforward for a number of reasons. Firstly, yield differences in wheat are more often associated with harvest index than with differences in radiation-use efficiency (Calderini et al., 1995). Where yields are primarily limited by assimilate supply, an association between photosynthetic capacity and performance cannot necessarily be expected. The possibility for genetic variation in the photosynthetic metabolism to environment should not be ruled out. Wheat like other crops fixes carbon through photosynthesis and releases the assimilated carbon through respiration, primarily night respiration, which determines the crop carbon balance. Once gross carbon fixation rate has been simulated, net carbon fixation can be calculated by estimating the cost of growth, maintenance, and photorespiration (Loomis and Amthor, 1996).

\section{Contribution of spike photosynthesis to grain filling in wheat}

Spike morphological traits are often unused as selection criteria in wheat breeding (Wang et al., 2016). However, the physiology of spikes is yet to be explored for improvement of genetic gain in productivity of wheat. Spike photosynthesis has a direct effect on grain yield (Tambussi et al., 2007; Xiao et al., 2011). Depending on genotype and treatment, the spike can contribute 10\%59\% of total grain weight (Li et al., 2017; Araus et al., 1993). The grain photosynthesis is able to account for $33-42 \%$ of this photosynthesis (Evans and Rawson, 1970). In another study, shading the ear decreased grain weight by $59 \%$ and genetic variation was observed for this parameter (Araus 
et al., 1993). A C4 photosynthetic pathway is present in the developing wheat grain that is absent in the leaves. The concept of the photosynthetic area above the flag leaf node in wheat as an important determinant of grain yield has existed for many years (Simpson et al. ,1968; Hsu and Walton, 1971); however, the role of spike photosynthesis has been omitted from analyses of the areas of specific photosynthetic modules with respect to their influence on grain yield. A correlation between spike weight and other morphological traits of spike have been reported (Maydup et al., 2007). Earlier it was proposed that the use of gigas spike types can boost potential grain number (Gaju et al., 2009) which can be a trait for increasing assimilation capacity of canopy of spikes. Parry et al., (2011) stated that the spike canopy photosynthesis proportion may be used as a trait in wheat breeding programs.

\section{Contribution of stem reserves to grain filling}

An increase in assimilate availability around anthesis is able to improve the distal grain weight [Roder et al., 2008]. Under harsh environments such as heat stress and water deficit, stem reserves as water soluble carbohydrates support grain development and hence productivity of wheat (Ehdaie et al., 2008; Gupta et al., 2011; Yang et al. 2000). Translocation of stem reserves contribute 20 to $40 \%$ weight of the grain in favourable condition (Saint Pierre et al., 2010) and this can be up to 70\% under stressed conditions during grain filling (Plaut et al., 2004; Rebetzke et al., 2008). Van Herwaarden et al. (1998) showed that under dry conditions in the field, the apparent contribution of stored assimilates could be more than $75 \%$ of grain yield as compared with $37-39 \%$ under high rainfall conditions. Ehdaie and Waines (1996) have reported that in wheat exposed to drought, almost $50 \%$ of the grain yield was estimated to derivate from re-translocated assimilates stored prior to anthesis. According to some studies stem reserves accounted for $64 \%$ and $81 \%$ of total grain $\mathrm{C}$ and $\mathrm{N}$, respectively under stress (Dreccer et al., 2009, Plaut $e t$ al., 2004, Van Riet et al., 2008).

A reduction in plant water status and photosynthesis caused by drought stress induces the conversion of stored reserves into soluble (transportable) sugars and mobilization of sugars into grains (Blum et al., 1994; Palta and Fillery 1995; Yang et al., 2001a, Plaut et al., 2004). This dehydration tolerance strategy is sustained even under severe chemical dessication of the plant (Blum et al., 1983; Hossain et al., 1990). The phloem translocation was unaffected until late in the stress period, whereas other processes, such as photosynthesisetc, were strongly inhibited (Farre et al., 2016). The temperature range of 1 to $50^{\circ} \mathrm{C}$ had no effect on the movement within the stem (Gebbing and Schnyder 1999). Because of this relative insensitivity, there is continuing translocation of assimilates, which could be a key ability for stress tolerance. Defoliation experiment and stem water soluble carbohydrate content of three high yielding local cultivars revealed that under water stress a significantly higher grain weight was retained by one cultivar (Lok1) due to higher stem reserve remobilization as compared to other two cultivars (Kumar et al., 2017).The genetic variability with respect to intra-spike variation in grain size can be one of the opportunity to improve grain weight per spike and hence to improve the productivity of wheat.

Wardlaw (1974) observed that the assimilate loading from leaves was maximum at $20-30^{\circ} \mathrm{C}$; however there was an abrupt decline above $30^{\circ} \mathrm{C}$. The conclusion was that the effect of high temperature on biomass partitioning in wheat was indirectly related to the abnormal behavior of source and sink along with the reduced photosynthesis rate. In a recent study by Ram K et al., (2018) genotypes with faster reserve mobilization showed maximum grain yield per meter square under unfavorable conditions and stipulated that stem reserve mobilization is best physiological strategy for selection of tolerant and high yielding genotypes for drought and high temperature conditions. Further, anatomical features which determine the ease of translocation of assimilates through phloem can offer additional opportunities for identification of relevant traits for improving performance of wheat under drought and high temperatures.

\subsection{Traits related to stem reserve mobilization under stress conditions}

Different traits have been associated with improved stem reserve remobilization (Fig. 2). Sufficient carbohydrate storage before grain filling is a major condition for stem reserves for grain filling. This may be associated to the traits that promote high yield potential, before anthesis. The stem reserve carbohydrates are termed as non-structural carbohydrates (NSCs) or water soluble carbohydrates (WSCs). NSCs include glucose, fructose, sucrose and fructan. Fructans are main components 
of NSCs in wheat stems (Rouska et al., 2006; Joudi et $a l ., 2012$ ) and constitute up to $85 \%$ of total NSCs at the maximum accumulation stage (Goggin et al. 2004), while sucrose accounts for only 10\% (Cruz-Aguado et al. 2000). In a study by (Dreccer et al. 2009) the individual grain weight, from the average pool and the contribution of WSC to yield was significantly greater in the high vs. low WSC lines. Therefore, a higher proportion of final average individual grain weight in high WSC crops was dependent on the pool of stored stem carbohydrates, $11.5 \%$ vs. $8.2 \%$ in low WSC lines. The drought tolerant cultivars have higher stem NSC than sensitive cultivars under both control and stress condition (Gupta et al. 2011). High WSC lines had a lower grain number per gram of spike weight or spike $\mathrm{N}$ at anthesis. This can be attributed to compensatory mechanisms between the grain number and grain weight. Nevertheless, it is worth investigating as to whether this could explain the differences in the spike

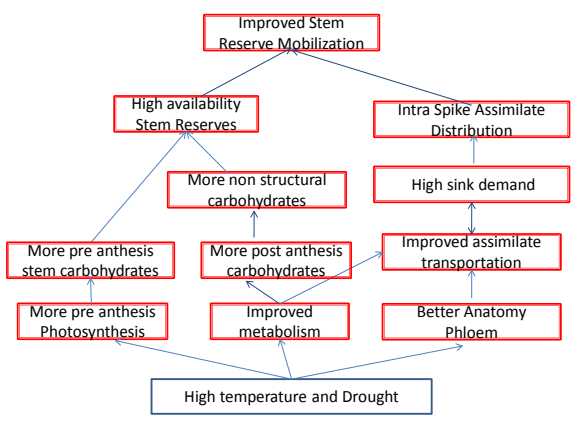

Fig. 2. Scope for improved stem reserve remobilization under high temperature and drought.

structure, such as larger rachis, for larger or faster delivery of sugars to the grains.

I

The accumulation of NSCs in stem begins at internode elongation from jointing to grain filling stage, but the total quantity depends on genotype and environment (Del pozo et al., 2016; Dreccer et al., 2009). NSC accumulation and remobilization varies in different internodes (Wardlaw et al. 1994; Shakiba et al. 1996). About 45\% of the maximum mass of the stem is present in peduncle and penultimate internode and 55\% is present in the lower internodes (Borrell et al., 1993). The maximum accumulation of NSCs occurs between the peduncle and penultimate internode (Dreccer et al., 2009; Zhang et al., 2015) but (Li et al., 2015) found that the lower internodes had higher water-soluble carbohydrate than those in peduncles. The WSC content in the lower internodes had highly significant correlations with thousand grain weight (TGW) at anthesis stage under non-stressed conditions and at the middle of grain filling period under water deficit. Thus, the length of lower internodes should be sufficient to store enough stem NSC to provide assimilates during the grain filling (Ehdaie et al., 2006a). At 21 DAA (days after anthesis), mobilization of photosynthate starts from the upper part of stem (such as peduncle and penultimate internode), but it starts earlier at 10 DAA from the lower part of stem in wheat (Ehdaie et al., 2008). Borrel et al., (1993)concluded that under irrigated conditions, plant height and mobilization of stem reserves are positively correlated. In a study by Saint Peirre et. al. (Gupta et al., 2011), stem solidness of different genotypes had a positive correlation with NSC per stem and grain yield. Blum (1998) stated that the ability to store carbohydrate in stem is determined by stem specific weight and stem length. Ehdaie et al., (2006) also reported that dry matter mobilized under well-watered and drought conditions correlated significantly and positively with maximum weight of internodes but there was no correlation between stem length and stem reserve mobilization in their study (Ehdaie et al .,2008). Earlier, Shakiba (1996) observed a negative correlation between specific weight of peduncle and penultimate internode and WSC content at anthesis under control and drought stress. According to Wang et al., (2012) under heat stress, the mobilization efficiency increases, partially compensating for reduced stem carbohydrates content. Zamani et al., (2014) observed that WSC remobilization increased by $60 \%$ on average under heat stress and different genotypes showed variation for WSC remobilization. The cultivars differ not only in the amount of mobilized assimilates but also in efficiency of mobilization in different internodes of the main stem (Ehdaie et al., 2006b).

\subsection{Techniques to estimate stem reserve contribution}

Different methods have been applied to determine the apparent contribution of stem reserves in grain yield.There is a strong positive correlation between stem dry matter and stem NSC content, therefore post-anthesis changes in stem dry weight in wheat is used as an effective indirect method to estimate the stem reserve remobilization to grain (Ehdaie et al., 2008).To reveal genotypic differences in the absence of photosynthesis Nicolas and Turner (1993) 
used a leaf spray of KI on wheat under post-anthesis stress. Other methods such as, inhibiting current photosynthesis during grain filling by defoliation (Fokar et al., 1998), labeling methods (Schnyder, 1992) or applying darkness (Yang et al., 2002) have also been used.

\subsection{Association of stem reserves with other processes}

Tahir et al., (2005) observed that heat stress significantly reduced the nitrogen remobilization efficiency of genotypes, however WSC remobilization efficiency increased and significant differences were observed among genotypes. Nitrogen remobilization efficiency under all conditions significantly correlated with grain yield, grain weight and grain filling duration. Palta et al., (1994) found that the remobilization of nitrogen was increased under water deficit; therefore, the grain $\mathrm{N}$ accumulation was not affected despite the reduction in $\mathrm{N}$ uptake post-anthesis. However, nitrogen mobilization depends on genotype and environmental conditions (Barraclough et al., 2010) They also observed that the NSC remobilization efficiency was positively correlated with grain weight and harvest index.

The rate of chlorophyll loss from flag leaf under heat stress positively correlated with nitrogen and NSC remobilization efficiencies suggesting a link between remobilization efficiency and senescence. Initiation of whole-plant senescence is a requirement for remobilization of stem water-soluble carbohydrates to grain in wheat as demonstrated by extensive studies (Yang et al., 2006). Early senescence induced by controlled soil drying could increase the rate of grain filling and improve kernel weight by improving remobilization of assimilates to grains. High temperature decreases the chlorophyll content in the leaves and accelerates senescence (Fokar et al., 1998). The link between accelerated leaf senescence and loss of chlorophyll from the leaves and the promotion of NSC remobilization from the stem is not clear. An increase in proteins related to stem senescence and reserve remobilization lead to higher stem reserve remobilization efficiency. Rapid leaf senescence may be an indication of reserve mobilization to the grain under stress (Assaf et al. 2014). Carbohydrate and nitrogen metabolism is involved in balancing stem reserve mobilization and nonsenescence, but the exact mechanisms are unknown. In addition, the predominance of proteins associated with ROS handling has been observed in order to sustain stem reserve remobilization under drought condition
(Bazargani et al.2011). Tillers contribute to final grain yield under high temperature conditions but the utilization of stem reserves in tillers as compared to the main stem is not known. Srivastava et al., (2017) observed that defoliation treatment hindered the capacity of the plants to remobilize their entire stem reserves to developing grains suggesting that grain filling might be source limited.

\subsection{Enzymes associated with stem reserve mobilization}

The enzymes involved in the stem reserve accumulation and mobilization are given in the table 1. Fructan is synthesized by four fructosyltransferase (FT) enzymes (Lammens et al., 2012; Cimini et al., 2015). The mobilization of stored reserves requires fructan hydrolysis, which is catalyzed by fructanexohydrolase (FEH) enzymes (Xue et al., 2008). Three enzymes take part in sucrose metabolism in the wheat stem:--Sucrose phosphate synthase, sucrose synthase (SS) and soluble acid invertase .Wardlaw and Willenbrink (2000) observed that under water stress, an early fall in fructancontent is coincident with a rise in fructanexohydrolase and acid invertase in the internodes. In case of rice and wheat, ADP-glucose pyrophosphorylase (AGPP) and SS activity in superior grains was higher than that of inferior grains (Yang et al., 2001a, Jiang et al., 2003). The enhanced SS activity in the grains of drought stressed plants of tolerant cultivar as compared to those of sensitive one increased the sink strength and attributed towards faster remobilization of assimilates to the grains. Sucrose synthase activity is therefore regarded as biological marker of sink strength (Xu et al., 2019).

\subsection{Role of plant hormones in assimilate translocation}

The hormone levels in grains have been significantly correlated with grain filling of wheat. Abscisic acid (ABA) and cytokinins are involved in regulation of seed development (Davies et al., 1987). ABA has been assumed to be important in regulation of the transport of reserves to the developing seeds or fruits (Tietz et al. 1981; Eewens et al., 1975). Many studies have reported a correlation between the ABA content and the growth rate of fruits or seeds (Schussler et al., 1991; Wang et al., 1987; Ross et al., 1990; Kato et al., 1993; Yang et al., 1999). Plant senescence is delayed by a high level of cytokinins (Buchanan-Wollaston, 1997; Nooden et al., 1997), whereas a high ABA concentration accelerates senescence and therefore control the time available for nutrient 
Table 1. Enzymes involved in the stem carbohydrate reserve metabolism.

\begin{tabular}{|c|c|c|}
\hline SNo & Enzyme & Function \\
\hline 1 & $\begin{array}{l}\text { 1-SST (sucrose:sucrose 1-fructos- } \\
\text { yltransferase) }\end{array}$ & Fructan biosynthesis: catalyzes the production of 1-ketose from sucrose \\
\hline 2 & $\begin{array}{l}\text { 1-FFT (fructan:fructan 1-fructosyl- } \\
\text { transferase) }\end{array}$ & $\begin{array}{l}\text { Fructan biosynthesis: sucrose alpha-glucosidase activity, transferase activ- } \\
\text { ity }\end{array}$ \\
\hline 3 & $\begin{array}{l}\text { 6-SFT (sucrose:fructan } 6 \text {-fructos- } \\
\text { yltransferase) }\end{array}$ & Fructan biosynthesis: sucrose $1 \mathrm{~F}$-fructosyltransferase activity \\
\hline 4 & $\begin{array}{l}\text { 6G-FFT (fructan:fructan } 6 \mathrm{G}-\text { fruc- } \\
\text { tosyltransferase) }\end{array}$ & $\begin{array}{l}\text { Fructan biosynthesis: sucrose alpha-glucosidase activity, transferase activ- } \\
\text { ity }\end{array}$ \\
\hline 5 & 1-fructan exohydrolase $(1-\mathrm{FEH})$ & $\begin{array}{l}\text { Fructan hydrolysis: catalyze the reaction of depolymerisation of fructan, } \\
\text { with }(2,1) \text { [Xue et al. 2008] }\end{array}$ \\
\hline 6 & 6 -fructan exohydrolase $(6-\mathrm{FEH})$ & $\begin{array}{l}\text { Fructan hydrolysis: catalyze the reaction of depolymerisation of fructan, } \\
\text { with }(2,6) \text { linkages[De Coninck et al. 2005; Van den Ende et al. 2004; } \\
\text { Van den Ende et al. 2006] }\end{array}$ \\
\hline 7 & $6 \& 1-\mathrm{FEH}$ & $\begin{array}{l}\text { Fructan hydrolysis: catalyze the reaction of depolymerisation of fructan, } \\
\text { with }(2,6) \text { and }(2,1) \text { linkages [Davies et al. 1987] }\end{array}$ \\
\hline 8 & Sucrose phosphate synthase & $\begin{array}{l}\text { Catalyzes sucrose synthesis and influences the movement of assimilates } \\
\text { from the source to the developing grains [Pinheiro et al 2005]. }\end{array}$ \\
\hline 9 & Sucrose synthase (SS) & $\begin{array}{l}\text { Catalyzes a reversible conversion of sucrose into fructose and uridine } \\
\text { diphosphate glucose [Gonzalez et al. 1998] attributed towards faster remo- } \\
\text { bilization of assimilates to the grains [37] }\end{array}$ \\
\hline 10 & Soluble acid invertase & Hydrolyzes sucrose into glucose and fructose [Thitisaksakul et al. 2012] \\
\hline
\end{tabular}

mobilization (Nooden, 1998; Madhu et al., 1999; Tadas et al., 1999). However, there are contradictory reports about the involvement of ABA in regulating both senescence and assimilate mobilization (Brown et al. 1991; Schussler et al. 1991; De Brujn and Vreugdenhil 1992; Sharp et al. 2002). Yang et al. (2003) observed that under water stress ABA was positively and significantly correlated with stem reserve remobilization and grain filling rate but zeatin $(\mathrm{Z})+$ zeatin riboside $(\mathrm{ZR})$ concentrations in the stems and leaves was reduced. Exogenous ABA increased the chlorophyll loss, enhanced the remobilization of prestored carbon from the stem to the endosperm, and increased grain weight (Yang et al. 2001b). An increase in ABA and reduction in cytokinin levels induces early senescence under drought in wheat and rice which leads to higher and faster stem NSC remobilization to grains and increases grain filling rate, but shortens the grain filling period (Yang et al. 2003; Yang et al. 2001). Exogenous kinetin reduced remobilization of carbohydrate reserves (Yang et $a l .2003)$. The hormone gibberellin is likely to be involved in induction of reserve mobilization under stress (Yang et al. 2001b). Superior grains have a higher level of ethylene
(ETH) than inferior grains of wheat (Yang et al. 2006a). A study found that plastic covered ridge and furrow planting significantly affected the Z $+\mathrm{ZR}$ and ETH levels in grains, and that promoted the grain filling of inferior grain of wheat (Liu et al. 2013a). Liang et. al. (2017) observed that high pre-anthesis NSC reserves led to an increase in $\mathrm{Z}+$ ZR content and decrease in ETH evolution rate in the inferior grain, which enhanced the sink strength and grain filling rate of the inferior grain of wheat.

\subsection{Genetic improvement of stem reserve mobilization}

Plaut et. al. (2004) found that under water deficit condition, rate of grain filling is more in the tolerant than in sensitive wheat cultivar. The favorable WSC alleles haveincreased from 1.13 in the pre-1960 to 4.41 in the post-2000 in wheat. This suggests that stem reserves contribution to grain yield has been indirectly taken into consideration. QTL studies showed that many genes control WSC accumulation and are important for grain size and stability (Rebetzke et al., 2008). Li et. al., (2015) identified 22 favourable alleles for stem water-soluble carbohydrates, out of which five loci individually contributed to significantly higher TGW. The 
gene expression analysis indicated that 1-FEH w3 was likely the main gene involved in the total 1-FEH enzyme activity. High rate of fructan degradation was positively correlated to 1-FEH w3 gene, therefore, to a higher stem WSC remobilization (Zang et al. 2015). The 1-FEH w3 Westonia allele contributes to high grain weight in drought stress during grain filling. A marker generated in the promoter region of $1-\mathrm{FEH}$ w3 is associated with high stem fructan remobilization capacity (Nicolas et al. 1993). Among the five sucrose transporter genes (SUTs) reported in wheat (Aoki et al. 2004; Deol et al. 2013; Mukherjee et al. 2015; Ahmed et al. 2018), the high gene expression of TaSUT1 in grain and the correlation with the grain filling demonstrated the crucial role for TaSUT1 in sucrose reloading to grain and high yield. Significant differences in TaSUT1 gene expression between treatments and varieties indicate the genotypic variations towards two different soil moisture levels.

\section{Conclusion}

Improving photosynthesis is an approach which targets increasing yield potential, but it will also be necessary to reduce the yield gap between favourable and unfavourable.

\section{References}

1. Araus JL, HR Brown, A Febrero, J Bort, MD Serret 1993. Ear photosynthesis, carbon isotope discrimination and the contribution of respiratory $\mathrm{CO}_{2}$ to differences in grain mass in durum wheat Plant Cell Environment 16: 383-392.

2. Acevedo E, Harris H \& Cooper PJM 1991. Crop architecture and water use efficiency in Mediterranean environments. In H. Harris, P.J.M. Cooper \& M. Pala, eds. Soil and crop management for improved water use efficiency in rainfed areas, Ankara, ICARDA 106-118.

3. Ahmed Sarah Al-Sheikh, J Zhang, W Ma and B Dell 2018. Contributions of TaSUTs to grain weight in wheat under drought. Plant Molecular Biology 98(45):333-347.

4. Aoki N, GN Scofield, XD Wang. et al.2004. Expression and localisation analysis of the wheat sucrose transporter TaSUT1 in vegetative tissues. Planta 219: 176-184. environments in order to provide resilience to abiotic stresses such as drought and high temperatures. While stem reserve mobilization has been extensively studied, spike photosynthetic contribution under stress conditions needs to be explored. It is evident that the stem reserve mobilization is an alternative strategy adopted by plants to compensate for the reduced capacity of leaf photosynthesis during stress. It is important to note that genetic variation exist for this trait which needs to be explored for wheat improvement. Components of stem reserve supply for grain development can offer opportunity to identify relevant traits to ensure grain yield stability across the target environments. In addition, it is essential to focus on genetic variation in contribution of current spike contribution to developing grains specifically with focus on intraspike assimilate distribution which needs attention.

\section{Acknowledgement}

The authors acknowledge ICAR-National Institute of Abiotic Stress Management, Pune, Banasthali Vidyapith, Rajasthan and ICAR-Indian Institute of Wheat and Barley Research, Karnal for providing all necessary support.

5. Assaf Distelfeld, RazAvni, AM Fischer. 2014. Senescence, nutrient remobilization, and yield in wheat and barley. Journal of Experimental Botany, 65(14): 3783-3798.

6. Peter B, H Jonathan, J Janina, L Bellido, R Parmar, S Shepherd, C Hawkesford and Malcolm. 2010. Nitrogen efficiency of wheat: Genotypic and environmental variation and prospects for improvement. European Journal of Agronomy. 33: 1-11.

7. Bazargani MM, E Sarhadi, AAS Bushehri, A Matros, HP Mock, MR Naghavi, V Hajihoseini, M Mardi, MR Hajirezaei, F Moradi, B Ehdaie and GH Salekdeh 2011. A proteomics view on the role of droughtinduced senescence and oxidative stress defense in enhanced stem reserves remobilization in wheat. Journal of Proteomics 74:1959-1973

8. Blum A, B Sinmena, J Mayer, G Golan and L Shpiler. 1994. Stem reserve mobilization supports wheat-grain filling under heat-stress. Australian Journal of Plant Physiology, 21: 771-781. 
9. Blum A. 1998. Improving wheat grain filling under stress by stem reserve mobilization. Euphytica 100: 77-83.

10. Borrás L, GA Slafer, ME Otegui. 2004. Seed dry weight response to source-sink manipulations in wheat, maize and soybean: a quantitative reappraisal. Field Crops Research, 86(2-3):131-46.

11. Borrell A, L Incoll and M Dalling. 1993. The influence of the Rht1 and Rht2 alleles on the deposition and use of stem reserve in wheat. Annals of Botany 71: 317-326

12. Brenner ML \& N Cheikh. 1995. The role of hormones in photosynthate partitioning and seed filling. In: PJ Davies (eds), Plant Hormones, Physiology, Biochemistry and Molecular Biology, 649-670. Kluwer Academic Publishers, Dordrecht, The Netherlands.

13. Blum A, J Mayer, G Golan. 1983. Chemical desiccation of wheat plants as a simulator of postanthesis stress: II. Relations to drought stress Field Crops Research 6: 149-155

14. Brown JH, G Paliyath \& JE Thompson.1991. Physiological mechanisms of plant senescence. In: FC Steward (eds) Plant Physiology; a Treatise, Vol. X: Growth and Development 227-275. Academic Press, London and New York.

15. Buchanan Wollaston V. 1997. The molecular biology of leaf senescence. Journal of Experimental Botany 48: 181-199.

16. Campbell KG, CJ Bergman, DG Gualberto, JA Anderson, MJ Giroux, G Hareland, et al.1999 Quantitative trait loci associated with kernel traits in a soft $\times$ hard wheat cross. Crop Science 1999; 39:1184-95.

17. Calderini DF, and GA Slafer. 1999. Has yield stability changed with genetic improvement of wheat yield? Euphytica 107: 51-59.

18. Calderini DF, S Torres Leó n, and GA Slafer. 1995. Consequences of wheat breeding on nitrogen and phosphorus yield, grain nitrogen and phosphorus concentration and associated traits. Annals of Botany (London) 76:315-322.
19. Calderini DF and Ortiz-Monasterio. 2003. Grain position affects grain macronutrient and micronutrient concentrations in wheat. Crop Science 43: 141-151.

20. Chang C, J Lu, HP CX Ma and G Sun. 2015. Copy Number Variation of Cytokinin Oxidase Gene Tackx4 Associated with Grain Weight and Chlorophyll Content of Flag Leaf in Common Wheat. PLoS One. ;10(12):e0145970

21. Cimini S, V Locato, R Vergauwen, A Paradiso, C Cecchini, L Vandenpoel, et al. 2015 Fructan biosynthesis and degradation as part of plant metabolism controlling sugar fluxes during durum wheat kernel maturation. Frontiers in Plant Science 6, 89

22. Cruz-Aguado JA, R Rodés, IP Pérez, M Dorado. 2000. Morphological characteristic and yield components associated with accumulation and loss of dry mass in the internodes of wheat. Field Crops Research, 66: 129-139.

23. Clifford PE, CE Offler and JW Patrick. 1986. Growth regulators have rapid effects on photosynthate unloading from seed coats of Phaseolus vulgaris L. Plant Physiology 80: 635-637.

24. Del Pozo A, A Ya 'ñez, I Matus, G Tapia, D Castillo, Sanchez-Jardo 'n L, et al. 2016 Field phenotyping of a worldwide germplasm collection of spring wheat under contrasting water conditions in a Mediterranean environment: relationships between physiological and agronomical traits. Frontiers in Plant Science 7: 987.

25. Deol KK, S Mukherjee, F Gao, A BrÛlé-Babel, C Stasolla, BT Ayele. 2013. Identification and characterization of the three homeologues of a new sucrose transporter in hexaploid wheat (Triticum aestivum L.). BMC Plant Biology 13: 181.

26. Dreccer MF, AF Herwaarden, SC Chapman. 2009. Grain number and grain weight in wheat lines contrasting for stem water soluble carbohydrate concentration. Field Crops Research 112: 43-54.

27. Driever SM, T Lawson, PJ Andralojc, CA Raines, MAJ Parry. 2014. Natural variation in photosynthetic capacity,growth,and yield in 64 field-grown wheat 
genotypes. Journal of Experimental Botany 2014; 65(17):4959-73.

28. Duan E, E Wang, L Liu, J Zhu, M Zhong, H Zhang et al. 2016. Pyrophosphate: fructose-6-phosphate 1-phosphotransferase (PFP) regulates carbon metabolism during grain filling in rice. Plant Cell Reports 35: 1321-1331. doi: 10.1007/s00299-0161964-4.

29. Davies PJ. 1987. Plant hormones and their role in plant growth and development. In: PJ Davies (eds) The Plant Hormones: Their Nature, Occurrence, and Functions 1-11. Martinus Nijhoff Publishers, Dordrecht, The Netherlands.

30. De Bruijn SM and D Vreugdenhil. 1992. Abscisic acid and assimilate partitioning to develop seeds. I. Dose abscisic acid influence the growth rate of pea seeds? Journal of Plant Physiology 140: 201-206.

31. De Coninck, B, et al., 2005. Arabidopsis AtcwINV3 and 6 are not invertases but are fructanexohydrolases (FEHs) with different substrate specificities. Plant Cell Environment 28: 432 - 443.

32. Eeuwens CJ and WW Schwabe. 1975. Seed and pod wall development in Pisumsativum L. in relation to exacted and applied hormones. Journal of Experimental Botany 26: 1-14.

33. Ehdaie B, GA Alloush, MA Madore and JG Waines. 2006a. Genotypic variation for stemreserves and mobilization in wheat. II Postanthesis changes in internode water-soluble carbohydrates. Crop Science 46: 2093-2103.

34. Ehdaie B, GA Alloush and JG Waines. 2008. Genotypic variation in linear rate of grain growth and contribution of stem reserves to grain yield in wheat. Field Crops Research 106: 34-43.

35. Ehdaie B, and JG Waines. 1996. Genetic variation for contribution of preanthesis assimilates to grain yield in spring wheat. Journal of Genetics and Breeding 50: $47-56$.

36. Evans L and HM Rawson. 1970. Photosynthesis and respiration by the flag leaf and components of the ear during grain development in wheat. Australian journal of biological sciences 23: 245-254.
37. Fokar M, A Blum, and HT Nguyen. 1998. Heat tolerance in spring wheat. II. Grain filling. Euphytica 104: $9-15$

38. Farré A, L Sayers, M Leverington-Waite, R Goram, S Orford, L Wingen et al. 2016. Application of a library of near isogenic lines to understand context dependent expression of QTL for grain yield and adaptive traits in bread wheat. BMC Plant Biology 2016; 16:1-13.

39. Foulkes MJ, JW Snape, VJ Shearman, MP Reynolds, O Gaju and R Sylverstar-Bradley. 2007. Genetic progress in yield potential in wheat: recent advances and future prospects. Journal of Agricultural Science 145: 17-29.

40. Gaju O, MP Reynolds, DL Sparkes, MJ Foulkes. 2009. Relationships between large-spike phenotype, grain number and yield potential in spring wheat, Crop Science, 49: 961-973.

41. Gupta AK, K Kaur, N Kaur. 2011. Stem reserve mobilization and sink activity in wheat under drought conditions. American Journal of Plant Science 2011; 2: 70-77.

42. Gu ZF, QS Zhu and X Z Cao. 1981. Studies on rate of grain ripening in rice. The relationship between dry weight accumulation in vigorous and weak spikelets and the distribution of sterile abortive grain (in Chinese). SciAgric Sin 14: 38-44.

43. Gebbing $\mathrm{T}$ and H Schnyder. 1999. Pre-anthesis reserve utilization for protein and carbohydrate synthesis in grain of wheat. Plant Physiology 1999; 121(3):871-878.

44. Goggin DE and TL Setter. 2004. Fructosyltransferase activity and fructan accumulation during development in wheat exposed to terminal drought. Functional Plant Biology 2004; 31:11.

45. Guo Y, IJ Sun, GZ Zhang, YY Wang, FM Kong et al. 2013. Haplotype, molecular marker and phenotype effects associated with mineral nutrient and grain size traits of TaGS1 a in wheat. Field Crops Research 2013; 154:119-25.

46. Groos C, N Robert, E Bervas, G Charmet. 2003. Genetic analysis of grain proteincontent, grain 
yield and thousand-kernel weight in bread wheat. Theoretical and Applied Genetics 2003; 106:1032-40.

47. Gonzalez EM, PM Aparicio-Tejo, AJ Gordon, FR Minchin. 1998. Water-deficit effects on carbon and nitrogen metabolism of pea nodules. Journal of Experimental Botany 49: 1705-1714

48. Han F, H Chen, XJ Li, MF Yang, GS Liu, SH Shen. 2009. A comparative proteomic analysis of rice seedlings under various high-temperature stresses, BBA-Proteins Proteom. 1794, 1625-1634.

49. Hasan AK, J Herrera, C Lizana, and DF Calderini 2011. "Carpel Weight, Grain Length and Stabilized Grain Water Content Are Physiological Drivers of Grain Weight Determination of Wheat." Field Crops Research 123 (3): 241-47.

50. Herzog H, and P Stamp. 1983. "Dry Matter and Nitrogen Accumulation in Grains at Different Ear Positions in 'Gigas', Semidwarf and Normal Spring Wheats." Euphytica 32 (2): 511-20.

51. Hossain ABS, RG Sears, TS Cox \& GM Paulsen. 1990. Desiccation tolerance and its relationship to assimilate partitioning in winter wheat. Crop Science 30: $622-627$

52. Hsu P and PD Walton. 1971. Relationships between yield and its components and structures above the flag leaf node in spring wheat Crop Science 11: 190-193

53. Hu MJ, HP Zhang, JJ Cao, XF Zhu, SX Wang, et al. 2016 Characterization of an IAA-glucose hydrolase gene TaTGW6 associated with grain weight in common wheat (Triticum aestivum L.). Molecular Breeding.; 36: 1-11.

54. Hanif M, FM Gao, JD Liu, WE Wen, YJ Zhang et. al. 2016 TaTGW6-A1, an ortholog of rice TGW6, is associated with grain weight and yield in bread wheat. Molecular Breeding.; 36:1.

55. Jiang, D, WX Cao, TB Dai, QJing. 2003. Activities of key enzymes for starch synthesis in relation to growth of superior and inferior grains on winter wheat (Triticum aestivum L.) spike. Plant Growth Regulators 41: 247-257.

56. Joudi M, AL Ahmadib, V Mohadi, A Abbasib, R Vergauwen, H Mohammadi, et al. 2012
Comparison of fructan dynamics in two wheat cultivars with different capacities of accumulation and remobilization under drought stress. Physiologia Plantarum 144: 1-12.

57. Kato T, N Sakurai and S Kuraishi. 1993. The changes of endogenous abscisic acid in developing grains of two rice cultivars with different grain size. Japanese Journal of Crop Science 62: 456-461.

58. Kirpa R, R kumar, Sunita and R Munjal. 2018. Stem Reserve Mobilization in Relation to Yield under Different Drought and High Temperature Stress Conditions in Wheat (Triticum aestivum L.) Genotypes. International Journal of Current Microbiology and Applied Sciences 2018. 7(4): 3695-3704

59. Kobata T, JA Palta and NC Turner. 1992. Rate of development of post anthesis water deficits and grain filling of spring wheat. Crop Science, 32: 1238-1242.

60. Liang W, Z Zhang, X Wen, Y Liao, Y Liu. 2017. Effect of non-structural carbohydrate accumulation in the stem pre-anthesis on grain filling of wheat inferior grain. Field Crops Research 211: 66-76 R.

61. Long SP, S Humphries and PG Falkowski. 1994. Photo inhibition of photosynthesis in nature. Annual Review of Plant Physiology and Plant Molecular Biology, 45: 633-664.

62. Loomis RS and JS Amthor. 1996. Limits of yield revisited. In M.P. Reynolds, S. Rajaram\& A. McNab, eds. Increasing yield potential in wheat: breaking the barriers, 76-89. Mexico, DF, CIMMYT.

63. Lammens W, K Le Roy, S Yuan, R Vergauwen, A Rabijns, A Van Laere, et al. 2012 Crystal structure of 6-SST/6-SFT from Pachysandra terminalis, a plant fructan biosynthesizing enzyme in complex with its acceptor substrate 6-kestose. The Plant Journal 70: 205-219.

64. Lee DG, N Ahsan, SH Lee, KY Kang, JD Bahk, IJ Lee, BH Lee. 2007. A proteomic approach in analyzing heat-responsiveproteins in rice leaves, Proteomics 7: 3369-3383.

65. Li YP, HB Li, YY Li, SQ Zhang. 2017. Improving water-use efficiency by decreasing stomatal conductance and transpiration rate to maintain 
higher ear photosynthetic rate in drought-resistant wheat Crop J., 5: 231-239

66. Law RD, SJ Crafts-Brandner, 2001. High temperature stress increases the expression of wheat leaf ribulose-1, 5-bisphosphate carboxylase/oxygenase activase protein, Arch. Biochem. Biophys. 386: 261-267.

67. Liao X, J Wang, R Zhou, Z Ren, J Jia. 2008. Mining favorable alleles of QTLs conferring thousand-grain weight from synthetic wheat. Acta Agron Sin. 2008; 34:1877-84

68. Ling HQ, SC Zhao, DC Liu, JY Wang, H Sun, et al. 2013. Draft genome of the wheat A-genome progenitor Triticumurartu. Nature. 2013; 496: 87-90.

69. Li W, B Zhang, R Li, X Chang, R Jing. 2015. Favorable Alleles for Stem Water-Soluble Carbohydrates Identified by Association Analysis Contribute to Grain Weight under Drought Stress Conditions in Wheat. PLoS ONE 10(3): e0119438.

70. Lynch JP, Doyle, S McAuley, McHardy, QD Lisa, C Black, M White, J Spink. 2017. The impact of variation in grain number and individual grain weight on winter wheat yield in the high yield potential environment of Ireland. European Journal of Agronomy 87: $40-49$

71. Ma DY, J Yan, ZH He, L Wu, XC Xia. 2012 Characterization of a cell wall invertase gene TaCwi-A1 on common wheat chromosome $2 \mathrm{~A}$ and development of functional markers. Molecular Breeding 29: 43-52.

72. Ma M, Q Wang, ZJ Li, HH Cheng, ZJ Li, et al. 2015 Expression of TaCYP78A3, a gene encoding cytochrome $\mathrm{P} 450 \mathrm{CYP78A} 3$ protein in wheat (Triticumaestivum L.), affects seed size. Plant Journal 2015; 83: 312-25.

73. Madhu A, G Thomas and N Edward. 1999. The roles of abscisic acid and ethylene in the abscission and senescence of cocoa flowers. Plant Growth Regulation 27: 149-155.

74. Michiels A, A Van Laere, W Van den Ende, M Tucker. 2004. Expression analysis of a chicory fructan 1exohydrolase gene reveals complex regulation by cold. Journal of Experimental Botany 55: 1325- 13333.
75. Mukherjee S, A Liu, KK Deol, K Kulichikhin, C Stasolla, A Brûlé-Babel, et al., 2015. Transcriptional coordination and abscisic acid mediated regulation of sucrose transport and sucrose-to-starch metabolism related genes during grain filling in wheat (Triticum aestivum L.). Plant Science 240: 143-160.

76. Mahrookashani A, S Siebert, H Huging, F Ewert. 2017. Independent and combined effects of high temperature and drought stress around anthesis on wheat. Journal of Agronomy and Crop Science 203:453463

77. Maydup ML, M Antonietta, JJ Guiamet, C Graciano, JR López, EA Tambussi. 2007. The contribution of ear photosynthesis to grain filling in bread wheat (Triticum aestivum L.) Field Crops Research 119: 48-58

78. Motzo R, S Fois, and F Giunta. 2004. Relationship between grain yield and quality of durum wheats from different eras of breeding. Euphytica, 140: 147-154.

79. Miralles DJ and GA Slafer. 1995. "Individual Grain Weight Responses to Genetic Reduction in Culm Length in Wheat as Affected by Source-Sink Manipulations.” Field Crops Research 43(2): 55-66.

80. Nicolas ME, NC Turner. 1993. Use of chemical desiccants and senescing agent to select wheat lines maintaining lines stable grain size during post-anthesis drought. Field Crop Research 1993, 31: 155-171.

81. Nooden LD, JJ Guiamet and I John. 1997. Senescence mechanisms. Physiologia Plantarum 101: 746-753.

82. Nooden LD 1988. Abscisic acid, auxin, and other regulators of senescence. In: LD Nooden \& AC Leopold (eds) Senescence and Aging in Plants, 329-368. Academic Press Inc, San Diego, Ca, USA.

83. Ortiz-Monasterio JI, KD Sayre, S Rajaram and M McMahon. 1997. Genetic progress in wheat yield and nitrogen use efficiency under four nitrogen rates. Crop Science 37: 898-904.

84. Plaut Z, BJ Butow, CS Blumenthal, CW Wrigley. 2004. Transport of dry matter into developing wheat kernels and its contribution to grain yield under postanthesis water deficit and elevated temperature. Field Crops Research 86, 185-198. 
85. Pradhan GP, PVV Prasad, AK Fritz, MB Kirkham and BS Gill. 2012. High temperature tolerance in Aegilops species and its potential transfer to wheat. Crop Science, 52: 292-304.

86. Palta JA, T Kobata, NC Turner and IR Fillery. 1994. Remobilization of carbon and nitrogen in wheat as influenced by post-anthesis water deficits. Crop Science, 34: 118-124.

87. Palta JA and Fillery IRP (1995) N application increases pre-anthesis contribution of dry matter to grain yield in wheat grown on a duplex soil. Australian Journal of Agricultural Research 46: 507-518

88. ParryMA, M Reynolds, ME Salvucci, C Raines, PJ Andralojc, XG Zhu, GD Price, AG Condon, RT Furbank. 2011. Raising yield potential of wheat. II. Increasing photosynthetic capacity and efficiency. Journal of Experimental Botany 62: 453-467.

89. Pinheir BDS, RB Austin, MPD Carmo, MA Hall. .2000. Carbon isotope discrimination and yield of upland rice as affected by drought at flowering. Pesqui. Agropecu. Brasil. 35: 1939-1947.

90. Pinheiro C, AP Rodrigues, IS de Carvalho, MM Chaves and CP Ricardo. 2005. Sugar metabolism in developing lupin seeds is affected by a short-term water deficit. Journal of Experimental Botany 56(420): 2705-2712.

91. Rasheed A, X Xia, F Ogbonnaya, T Mahmood, Z Zhang, A Mujeeb-Kazi, et al. 2014. Genomewide association for grain morphology in synthetic hexaploid wheats using digital imaging analysis. $B M C$ Plant Biology 14(1):128.

92. Röder MS, XQ Huang, A Börner. 2008. Fine mapping of the region on wheat chromosome 7D controlling grain weight. Functinal and Integrative Genomics 2008; 8:79-86.

93. Reynolds MP, A Pellegrineschi, B Skovmand. 2005. Sink-limitation to yield and biomass: a summary of some investigations in Spring wheat.Annals of Applied Biology 2005; 146(1):39-49.

94. Ruuska SA, GJ Rebetzke, AF van Herwaarden, RA Richards, NA Fettell, L Tabe, et al. 2006. :Genotypic variation in water-soluble carbohydrate accumulation in wheat. Functional Plant Biology 33: 799- 809 .

95. Rebetzke GJ, AF van Herwaarden, C Jenkins, M Weiss, D Lewis, S Ruuska, L Tabe, NA Fettell and RA Richard. 2008. Quantitative trait loci for soluble stem carbohydrate production in wheat. Australian Journal of Agricultural Research 59: 891-905.

96. Rane J, RK Pannu, VS Sohu, RS Saini, B Mishra, J Shoran, J Crossa, M Vargas, K Joshi. 2007. Performance of yield and stability of advanced wheat cultivar under heat stress environments of the indogangetic plains. Crop Science 47: 1561-1572.

97. Ross GS and JA McWha. 1990. The distribution of abscisic acid in Pisumsativum plants during seed development. Journal of Plant Physiology 136: 137-142.

98. Schussler JR, ML Brenner and WA Brun. 1991. Relationship of endogenous abscisic acid to sucrose level and seed growth rate of soybeans. Plant Physiology 96: 1308-1313.

99. Schnyder H. 1993. The role of carbohydrates storage and redistribution in the source-sink relations of wheat and barley during grain filling- a review. New Phytologist, 123: 233-245.

100. Samonte SOPB, LT Wilson, Am McClung, L Tarpley. 2001. Seasonal dynamics of non-structural carbohydrate partitioning in 15 diverse rice genotypes. Crop Science 41: 902-909.

101. Sharp RE and ME LeNoble. 2002. ABA, ethylene and the control of shoot and root growth under water stress. Journal of Experimental Botany 53: 33-37.

102. Serrago RA, I Alzueta, R Savin, GA Slafer. 2013. Understanding grain yield responses to source-sink ratios during grain filling in wheat and barley under contrasting environments. Field Crops Research 2013; 150(0): 42-51.

103. Shakiba MR, B Ehdaie, MA Madore. 1996. Contribution of internode reserves to grain yield in a tall and semidwarf spring wheat. Journal of Genetic Breeding 50: 91-100

104. Srivastava A, P Srivastava, A Sharma, RS Sarlach and NS Bains. 2017. Effect of stem reserve mobilization on grain filling under drought stress conditions in 
recombinant inbred population of wheat. Journal of Applied and Natural Science 9(1): 1-5

105. Su ZQ, CY Hao, LF Wang, YC Dong, XY Zhang. 2011. Identification and development of a functional marker of TaGW2 associated with grain weight in bread wheat (Triticum aestivum L.). Theoretical and Applied Genetics 122: 211-23.

106. Sylvester-Bradley, RK Scott, CE Wright Physiology in the production and improvement of cereals. Home-Grown Cereals Authority Research Review, 18, HGCA, London (1990)

107. Seaton, GR and DA Walker. 1990. Chlorophyll fluorescence as a measure of photosynthetic carbon assimilation. Proceedings of Royal Society, Lond. B, 242: 29-35.

108. Saint Pierre C, RM Trethowan, M Reynolds. 2010. Stem solidness and its relationship to water-soluble carbohydrates: association with wheat yield under water deficit. Functional Plant Biology, 37(2): 166-174

109. Schnyder H 1992 Long-term steady-state labelling of wheat plants by use of natural $13 \mathrm{CO} 2 / 12 \mathrm{CO} 2$ mixtures in an open, rapidly turned-over system. Planta 187: 128-135.

110. Sabehat A, S Lurie, D Weiss. 1998. Expression of small heat-shock proteins at low temperatures a possible role in protecting against chilling injuries, Plant Physiology 117:(1998) 651-658.

111. Simpson G. Association between grain yield per plant and photosynthetic area above flag leaf node in wheat Can.J. Res., 48: (1968) 253-260

112. Sadras VO and DB Egli. (2008). Seed size variation in grain crops: Allometric relationships between rate and duration of seed growth. Crop Science, 48: 1-8.

113. Simmons R and DN Moss. 1978. Nitrogen and drymatter accumulation by kernels formed at specific florets in spikelets of spring wheat. Crop Science 18:139-143.

114. Schussler JR, ML Brenner and WA Brun. 1991. Relationship of endogenous abscisic acid to sucrose level and seed growth rate of soybeans. Plant Physiology 96: 1308-1313.
115. Tahir ISA and N Nakata. 2005. Remobilization of nitrogen and carbohydrate from stems of bread wheat in response to heat stress during grain filling. Journal of Agronomic Crop Science 191: 106-115.

116. Tambussi EA, J Bort,JJ Guiamet, S Nogues, JL Araus. 2007. The photosynthetic role of ears in C 3 cereals: metabolism, water use efficiency and contribution to grain yield, Critical Reviews in Plant Sciences, 26:1-16

117. Tadas P, P Agata, DR Philip, R Bernard and LW Elsbeth. 1999. Identification of senescence associated genes from daylily petals. Plant Molecular Biology 40: 237-248.

118. Tietz A, M Ludwig, M Dingkuhn and K Dorffling. 1981. Effect of abscisic acid on the transport of assimilates in barley. Planta 152: 557-561.

119. Thitisaksakul M, RC Jiménez, MC Arias, D Beckles.2012. Effects of environmental factors on cereal starch biosynthesis and composition. Journal of Cereal Science 56: 67-80.

120. Van Riet L, V Nagaraj, W Van den Ende, S Clerens, A Wiemken, A Van Laere. 2006. Purification, cloning and functional characterization of a fructan 6-exohydrolase from wheat (Triticum aestivum L.). Journal of Experimental Botany 57: 213-223.

121. Van Riet L, D Altenbach, R Vergauwen, S Clerens, A Kawakami, M Yoshida, et al. 2008. Purification, cloning and functional differences of a third fructan 1-exohydrolase (1-FEHw3) from wheat (Triticum aestivum). Physiologia Plantarum 133: 242-253.

122. Van den Ende W, B De Coninck, A Van Laere. 2004. Plant fructanexohydrolase: a role in signaling and defense? Trends in Plant Science 9: 523-528.

123. Van den Ende W, S Clerens, R Vergauwen, D Boogaerts, K Le Roy, L Arckens, et al. 2006. Cloning and functional analysis of a high DP fructan: fructan 1-fructosyltransferase from Echinopsritro (Asteraceae): comparison of the native and recombinant enzymes. Journal of Experimental Botany 57: 775- 789.

124. Vignjevic, M, X Wang, J Olesen and B Wollenweber. 2015. Traits in spring wheat cultivars associated with yield loss caused by a heat stress episode after anthesis. Journal of Agronomic Crop Science, 201: 32-48 
125. Wardlaw IF, J Willenbrink. 1994. Carbohydrate storage and mobilization by the culm of wheat between heading and grain maturity: the relation to sucrose synthase and sucrose-phosphate synthase. Functional Plant Physiology 21: 255-272.

126. Wang E, J Wang, X Zhu, W Hao, L Wang, Q Li, et al. 2008. Control of rice grain-filling and yield by a gene with a potential signature of domestication. Nature Genetics 40: 1370-1374. doi: 10.1038/ng.220

127. Wang TL, SK Cook, RJ Francis, MJ Ambrose and CL Hedley. 1987. An analysis of seed development in Pisumsativum. VI. Abscisic acid accumulation. Journal of Experimental Botany 38: 1921-1932.

128. Xue GP, CL Mclntyre, LD Colin, CLD Jenkins, D Glassop, AF van Herwaarden, et al. 2008 Molecular dissection of variation in carbohydrate metabolism related to water-soluble carbohydrate accumulation in stems of wheat. Plant Physiology 146: 441-45.

129. Wang X, BS Dinler, M Vignjevic, S Jacobsen and B Wollenweber. 2015. Physiological and proteome studies of responses to heat stress during grain filling in contrasting wheat cultivars. Plant Science 230: 33-50.

130. Wardlaw IF, J Willenbrink,. 2000. Mobilization of fructan reserves and changes in enzyme activities in wheat stems correlate with water stress during kernel filling. New Phytologist 148: 413-422

131. Xie Q, S Mayes, D Sparkes. 2015.Carpel size, grain filling, and morphology determine individual grain weight in wheat. Journal of Experimental Botany 66 (21): 6715-6730.

132. Xu X, Y Yang, C Liu. et al. 2019. The revolutionary history of the sucrose synthase gene family in higher plants. BMC Plant Biology 19: 566.

133. XiaoY S, He, J Yan, Y Zhang, Y Zhang, Y Wu, X Xia, J Tian, W Ji and Z He. Molecular mapping of quantitative trait loci for kernel morphology traits in a non-L.1RS $\times 1$ BL.1RS wheat cross. Crop Pasture Science 2011 62: 625-638

134. Yang JC, JH Zhang, ZQ Wang, QS Zhu, LJ Liu. 2003. Involvement of abscisic acid and cytokinins in the senescence and remobilization of carbon reserves in wheat subjected to water stress during grain filling Plant Cell \& Environment 26(10): 1621-1631

135. Yang JC, JH Zhang, ZQ Wang, QS Zhu, W Wang. $2001 \mathrm{~b}$. Hormonal changes in the grains of rice subjected to water stress during grain filling. Plant Physiology 127: 315-323

136. Yang, JC, JH Zhang. 2006a. Grain filling of cereals under soil drying. New Phytologist 169: 223-236

137. Yang JC, JH Zhang, ZQ Wang, QS Zhu, W Wang,. 2001a. Remobilization of carbon reserves in response to water deficit during grain filling of rice. Field Crops Research 71: 47-55.

138. Yang J, Zhang J. Grain filling of cereals under soil drying. New Phytologist 2006; 169: 223-236.

139. Yang J, Zhang J, Wang Z, Zhu Q, Liu L. 2003 Involvement of abscisic acid and cytokinins in the senescence and remobilization of carbon reserves in wheat subjected to water stress during grain filling. Plant Cell Environment 2003; 26: 1621-1631.

140. Yang J, Zhang J, Wang Z, Zhu Q, Wang W. 2001 Hormonal changes in the grains of rice subjected to water stress during grain filling. Plant Physiology 2001; 127: 315-323.

141. Yang DL, Jing RL, Chang XP, Li W.2007 Identification of quantitative trait loci and environmental interactions for accumulation and remobilization of water-soluble carbohydrates in wheat (Triticum aestivum L.) stems. Genetics 176: 571-584. pmid:17287530

142.Zhang J, Y Xu, W Chen, B Dell, R Vergauwen, B Biddulph, et al. 2015b. A wheat 1-FEH w3 variant underlies enzyme activity for stem WSC remobilization to grain under drought. New Phytologist 205: 293-305.

143. Yan W, Y Zhong, Z Shangguan. 2016. A meta-analysis of leaf gas exchange and water status responses to drought. Scientific Reports 6: 20917.

144. Wang YQ, WX Xi, ZM Wang, B Wang, XX Xu, MK Han, SL Zhou, YH Zhang. 2016. Contribution of ear photosynthesis to grain yield under rainfed and irrigation conditions for winter wheat cultivars released in the past 30 years in North China plain Journal of Integrative Agriculture 15: 2247-2256 
145. Wang W, B Vinocur, A Altman. 2003. Plant responses to drought, salinity and extreme temperatures:towards genetic engineering for stress tolerance, Planta 218: $1-14$.

146. Wang Z, J Yang, Q Zhu, Z Zhang, Y Lang and X Wang. 1998. Reasons for poor grain filling in intersubspecific hybrid rice. Acta Agronomica Sinica 24: 782-787.

147. Yang J, Z Wang, QZhu and Y Lang. 1999. Regulation of ABA and GA to rice grain filling.Acta Agronomica Sinica 25: 341-348.

148. Wang LF, HM Ge, CY Hao, YS Dong, XY Zhang. 2012. Identifying loci influencing 1,000-kernel weight in wheat by microsatellite screening for evidence of selection during breeding. PLoS One. 2012;7(2):e29432.

149. Yan SP, QY Zhang, ZC Tang, WA Su, WN Sun. 2006. Comparative proteomic analysis provides new insights into chilling stress responses in rice, Molecular and Cellular Proteomics 5: 484-496.

150. Yang, J., Sears, R. G., Gill, B. S. and Paulsen, G. M. 2002. Genotypic differences in utilization of assimilate sources during maturation of wheat under chronic heat and heat shock stresses. Euphytica, 125: 179- 188.

151. Yang J and J Zhang. 2010. Grain filling problem in “super" rice. Journal of Experimental Botany 61: 1-5.
152. Yang, J., Zhang, J., Huang, Z., Zhu, Q. and Wang, L. 2000. Remobilization of carbon reserves is improved by controlled soil-drying during grain filling of wheat. Crop Science 40(4), 16451655.

153. Yu M, Chen G, Zhang L, Liu Y, Liu D, Wang J, et al. 2014 QTL mapping for important agronomic traits in synthetic hexaploid wheat derived from Aegiliopstauschii ssp. tauschii. Journal of Integrative Agriculture 2014;13:1835-44.

154.Zhang J, Chen W, Dell B, Vergauwen R, Zhang X, Mayer JE, Van den End 2015 Wheat genotypic variation in dynamic fluxes of WSC components in different stem segments under drought during grain filling. Frontiers in Plant Science 6: 624.

155.Zhang B, Li W, Chang X, Li R, Jing R 2014 Effects of Favorable Alleles for Water-Soluble Carbohydrates at Grain Filling on Grain Weight under Drought and Heat Stresses in Wheat. PLoS ONE 9(7): e102917

156.Zamani, M.M., M. Nabipour and M. Meskarbashee (2014) Stem water soluble carbohydrate remobilization in wheat under heat stress during the grain filling. Int. J. Agric. Biol., 16: 401-405

157. Zhang J, W Chen, B Dell, R Vergauwen, X Zhang, JE Mayer, Van den End. 2015. Wheat genotypic variation in dynamic fluxes of WSC components in different stem segments under drought during grain filling. Frontiers in Plant Science 6: 624. 